\title{
Challenges of implementing economic model predictive control strategy for buildings interacting with smart energy systems
}

Zong, Yi; Böning, Georg Martin; Santos, Rui Mirra; You, Shi; Hu, Junjie; Han, Xue

Published in:

Applied Thermal Engineering

Link to article, DOI:

10.1016/j.applthermaleng.2016.11.141

Publication date:

2016

Document Version

Peer reviewed version

Link back to DTU Orbit

Citation (APA):

Zong, Y., Böning, G. M., Santos, R. M., You, S., Hu, J., \& Han, X. (2016). Challenges of implementing economic model predictive control strategy for buildings interacting with smart energy systems. Applied Thermal Engineering, 114, 1476-1486. https://doi.org/10.1016/j.applthermaleng.2016.11.141

\section{General rights}

Copyright and moral rights for the publications made accessible in the public portal are retained by the authors and/or other copyright owners and it is a condition of accessing publications that users recognise and abide by the legal requirements associated with these rights.

- Users may download and print one copy of any publication from the public portal for the purpose of private study or research.

- You may not further distribute the material or use it for any profit-making activity or commercial gain

- You may freely distribute the URL identifying the publication in the public portal 
Research Paper

\title{
Challenges of implementing economic model predictive control strategy for buildings interacting with smart energy systems
}

\author{
Yi Zong ${ }^{\mathrm{a}, *}$, Georg Martin Böning ${ }^{\mathrm{b}}$, Rui Mirra Santos ${ }^{\mathrm{c}}$, Shi You ${ }^{\mathrm{a}}$, Junjie $\mathrm{Hu}^{\mathrm{a}}$, Xue Han ${ }^{\mathrm{a}}$ \\ ${ }^{a}$ Centre for Electric Power and Energy, Department of Electrical Engineering, Technical University of Denmark, Risø Campus, Frederiksborgvej 399, 4000 Roskilde, Denmark \\ ${ }^{\mathrm{b}}$ Berlin Energy Agency, Brümmerstr. 74, 14195 Berlin, Germany \\ ' IDMEC, Instituto Superior Técnico, Universidade de Lisboa, Av. Rovisco Pais, 1049-001 Lisbon, Portugal
}

\section{H I G H L I G H T S}

- EMPC for buildings integrated into smart energy systems were summarized in detail.

- The challenges on how to implement EMPC in practice were investigated.

- Implementing a stationary Kalman filter to overcome the uncertainty.

- Adding soft constraints to ensure feasible solutions for optimization problems.

- EMPC outperformed the traditional PID schemes for energy saving and load shifting.

\section{A R T I C L E I N F O}

\section{Article history:}

Received 4 April 2016

Revised 7 November 2016

Accepted 20 November 2016

Available online $\mathrm{xxxx}$

\section{Keywords:}

Active smart building

Data availability

Economic model predictive control

Modelling

Optimization

State estimation

\begin{abstract}
A B S T R A C T
When there is a high penetration of renewables in the energy system, it requires proactive control of large numbers of distributed demand response resources to maintain the system's reliability and improve its operational economics. This paper presents the Economic Model Predictive Control (EMPC) strategy for energy management in smart buildings, which can act as active users interacting with smart energy systems. The challenges encountered during the implementation of EMPC for active demand side management are investigated in detail in this paper. A pilot testing study shows energy savings and load shifting can be achieved by applying EMPC with weather forecast and dynamic power price signals.
\end{abstract}

(C) 2016 Published by Elsevier Ltd.

\section{Introduction}

In Denmark as well as in many other countries, fluctuating renewable energy sources (RESs) account for an increasing share of power generation. As a leading wind power country, Denmark has achieved a record of $42 \%$ penetration of wind power in 2015 , and the nation is well on its way to hitting its 2020 energy goals-50\% of traditional electricity supply must come from wind power [1]. According to Danish government's energy policy, oil burners and coal must be phased out of power plants in Denmark no later than 2030. By 2050, the entire supply of energy and transportation sectors will be provided by RESs [2]. In order to ensure that the transition to a greener economy is a good investment, RESs must be intelligently integrated into the energy system.

\footnotetext{
* Corresponding author.

E-mail address: yizo@elektro.dtu.dk (Y. Zong).
}

A smart energy system is a cost-effective, sustainable and secure energy system in which renewable energy production, infrastructures and consumption are integrated and coordinated through energy services, active users and enabling technologies [3]. This integration requires more flexibility in the entire energy system, and it will challenge the existing energy (electricity, heat, transportation and gas) infrastructure and its control systems with more complicated dynamics and uncertain problems. One of the important flexibilities is distributed energy resources (DERs) located at the demand side, and these DERs need better control and management to get their values maximized.

Buildings are the largest energy consuming sector in the world, and account for over one-third of total final energy consumption and an equally important source of $\mathrm{CO}_{2}$ emissions [4]. In the Nordic countries, buildings account for up to $40 \%$ of society's energy demand, and the energy is mainly used for heating, lighting, and electrical appliances. The thermal mass of buildings is "for free" 
and can provide a very large possibility for flexibility. Therefore, buildings play a key role in the green transition, and smart buildings can extend beyond the buildings themselves when they act as flexible components in a diverse energy system [5]. The projects presented in [6-8] are examples of buildings that hold the potential needed for energy efficiency and flexibility to be integrated in the smart energy system of tomorrow.

Model Predictive Control (MPC) is a control algorithm that optimizes a sequence of manipulated variable adjustments over a prediction horizon by utilizing a process model to optimize forecasts of process behaviour based on a linear or quadratic objective, which is subjected to equality or inequality constraints [9]. In MPC, the optimization is performed repeatedly on-line. This is the meaning of receding horizon, and the intrinsic difference between MPC and the traditional optimal control. The receding horizon optimization can effectively incorporate the uncertainties incurred by model-plant mismatch, time-varying behaviour and disturbances [10]. MPC is now recognized as a powerful approach with well-established theoretical foundations and proven capability to handle a large number of industrial control problems [11].

Recently, MPC has drawn the attention of the energy system community, because it is based on future behaviour of the system and predictions, which is appealing for systems significantly dependent on forecasting of energy demand and RES generation; moreover, it provides a feedback mechanism, which makes the system more robust against uncertainty [12-14]. The MPC strategies, that employ an economic-related objective function for real-time control, have lately proved a numerically efficient approach to managing the portfolio of energy usage with provable stability properties [15,16]. It is designated as an economic MPC (EMPC), which always copes with dynamically changing energy prices. Unlike the traditional MPC, EMPC optimizes the process operations in a time-varying manner, rather than maintain the process variables around a few desired steady states or tracking the reference. The process may thus totally operate in the transient state with EMPC [17]. EMPC for building temperature control has been investigated in several papers [18-22] that mainly with the purpose of increasing the energy efficiency in the buildings. Most of the results of the aforementioned literatures are based on the simulation study; however, the application of EMPC requires extensive knowledge in the areas of data processing, modelling, hardware and communication, state estimation, controller architecture design and optimization, which are highlighted and discussed in detail in this paper.

The remaining of this paper is organized as follows: in Section 2, the detailed EMPC strategy for smart buildings active interaction with the smart energy system is described, followed by a summary of the challenges encountered when we implement EMPC in practice. Section 3 presents how to implement EMPC in a residential building for a pilot testing. The testing results and analysis of running the EMPC controller on a test platform are discussed in Section 4. Finally, Section 5 concludes the paper and discusses the future research.

\section{EMPC for active smart buildings}

\subsection{EMPC strategy}

The EMPC is a variant of the classical MPC. It performs a dynamic economic optimization of the process with the objective of minimizing the costs [23]. In traditional tracking control, the objective is to minimize the error between a reference trajectory and the measured output. EMPC enables to define temperature bands or comfort zones realized by output constraints. The same as classical MPC, at each step, a look-ahead finite-horizon optimal control problem in EMPC is solved, but only the first step of control sequences is implemented. In addition, the hard constraints can be changed to the soft constraints to ensure feasibility in the linear optimization by adding a term to the cost function that penalizes constraint violation to obtain better controller performance. It was also proved that any stabilizable system can be asymptotically stabilized with soft constraints and state feedback [24]. The EMPC problem with soft constraints (grey coloured) can be expressed as linear program in the following form:

$$
\begin{aligned}
& \min _{\left\{u_{k}, v_{k+1}\right\}_{k=0}^{N-1}} \phi=\sum_{k=0}^{N-1} c_{k}^{\prime} u_{k}+\sum_{k=1}^{N} \rho V_{k} \\
& \text { subject to : } \quad x_{k+1}=A x_{k}+B u_{k}+E \omega_{k} \quad k=0,1, \ldots,(\mathrm{N}-1) \\
& y_{k}=C x_{k}+v_{k} \quad k=1,2, \ldots, \mathrm{N} \\
& u_{\min } \leqslant u_{k} \leqslant u_{\max } \quad k=0,1, \ldots,(\mathrm{N}-1) \\
& \Delta u_{\min } \leqslant \Delta u_{k} \leqslant \Delta u_{\max } \quad k=0,1, \ldots,(\mathrm{N}-1) \\
& z_{k}^{\min } \leqslant y_{k} \leqslant z_{k}^{\max } \quad k=1,2, \ldots, \mathrm{N} \\
& s_{k}^{\min } \leqslant y_{k}-v_{k} \leqslant s_{k}^{\max } \quad k=1,2, \ldots, \mathrm{N} \\
& v_{k} \geqslant 0 \quad k=1,2, \ldots, \mathrm{N}
\end{aligned}
$$

where $\boldsymbol{x}_{\boldsymbol{k}}$ is the state vector; $\boldsymbol{u}_{\boldsymbol{k}}$ is the manipulated input vector; $\boldsymbol{w}_{\boldsymbol{k}}$ is the process noise; $\boldsymbol{y}_{\boldsymbol{k}}$ is the measurement vector; $\boldsymbol{\rho}$ is the cost of breaking the constraints and $\boldsymbol{v}_{\boldsymbol{k}}$ is the vector of slack variables.

\subsection{Challenges of EMPC implementation for active smart buildings}

According to the authors' experience on the implementation of EMPC, it presents considerable challenges in data analysis, modelling, hardware and communication, optimization technique and state estimation, etc. The investigations on these challenges are summarized in the following sub-sections.

\subsubsection{Data availability and analytics}

EMPC requires not only an appropriate model, but also a wealth of input data during operation. Active buildings installed with smart meters and advanced building systems generate significant real-time or near-real-time data on energy usage and occupancy. The expansion of data including forecast data (weather, load, and energy price) presents great opportunities to improve building energy management practices, but the data collected is valuable only if it is analysed consistently and communicated effectively to both building decision-makers and distribution system operators (DSOs). For example, currently, the available time interval of the day-ahead Elspot electricity price signals from Nordpool market [25] is hourly-based; while the available weather forecast data are in 10-15 min interval.

For the building data management, it is important to focus on the data worth collecting, the analysis worth sharing, and analytical tools for the coordination control on DERs. This is a timeconsume and important preparation for the modelling and EMPC controller design.

\subsubsection{Modelling}

When large measurement data sets are available, a purely statistical approach for creation of a building model is preferred. EMPC inherently requires an appropriate model of the controlled plant, which is then used for the computation of the optimal control inputs. The relevant dynamic behaviour of the buildings for the active demand side management (ADSM) control tasks can be 
divided into the thermal dynamics (room temperatures, thermal capacities, heat inputs and losses) as well as the relevant building resources to provide corresponding services, such as heating, cooling, lighting, ventilation, photovoltaic (PV) systems or storage (batteries and electric vehicles). The model for active buildings must be sufficiently precise, in order to yield valid predictions of the relevant variables (e.g. room temperatures), but at the same time, the model must be as simple as possible for the optimization task to be computationally tractable and numerically stable.

To ensure adaptive autonomous operation on the building EMPC controller, the building thermal models should have the ability to be adjusted at least with the season's change. According to the application needs, models with different fidelity and mathematical properties will be used, based on a combination of physics-based approaches and data-driven approaches.

Normally, it is much more suitable to use Linear Time Invariant (LTI) models for the MPC controller design. This results in a convex optimization problem that in general can be well solved by stateof-the-art optimization software. Obtaining an appropriate LTI model of the controlled building is, however, a delicate and laborious task even for experienced and knowledgeable engineers. The following three approaches are in principle available [26]:

\section{(a) Black-box modelling}

A black box modelling considers the system as a box with inputs and outputs, its basis is the experimental data without having any prior knowledge of the system. More specifically, the physical description of the procedure is not available. The black-box approach is conceptually simple but technically tricky, and it depends crucially on the availability of appropriate input data sets.

\section{(b) White-box modelling}

A white-box model allows defining a complete description of the system, which means that the prior knowledge of the physics is essential for the model. In building case, it requires availability and processing of a large amount of building-specific information. For example, a number of specified equations are needed to formulate the deterministic physical model based on a good understanding of the heat dynamics in the building.

In general, the white-box models require very detailed data and these models will be much complicate due to the complex nature of many systems and processes. Many physical systems can only be described by complex sets of equations, which make this approach not so efficient.

\section{(c) Grey-box modelling}

Grey-box modelling is an approach between a black-box and white-box modelling. A grey-box model consists in differential stochastic equations building upon the prior knowledge of the physical dynamics of the system. The purpose of this approach is to provide a way of combining the advantages of both model types by allowing prior physical knowledge to be incorporated and statistical methods for parameter estimation to be applied. The information from the data can be used for the unknown parameter estimation by creating a discrete measurement equation. The data has to be "informative", which means that the measured signals must vary enough due to variation on the input signals. A commonly used input signal is a pseudo random binary (PRBS) signal [27]. In a word, grey-box models are not only physically interpretable but they also use real time data, which make it easier to implement for short and long- term predictions.

Refs. [27-29] show that using grey-box modelling, together with resistance capacitance $(\mathrm{RC})$ networks based on the principle of thermal dynamics, to build control-oriented models, is an effective approach for the modelling of the thermal dynamics of the buildings. RC networks (see the example in Section 3.1) use lumped capacitance and resistance in an analogy electric circuit to represent the thermal elements of a building. The resultant models can be transformed into state-space forms, which are available for the implementation of an EMPC.

However, when implemented for real-world buildings, such approaches face application problems, mainly because the thermal dynamics of a real building is nonlinear in characteristic and contains several uncertainties [30,31]. These result in non-convex optimization problems, which are hard to solve. Even they are solved but the computation is demanded, which is not suitable for the real-time operation. Ref. [32] proposed an neural network feedback linearization-based MPC to achieve energy-saving for a commercial building, which can convert the nonlinear control problem into a linear control problem.

\subsubsection{Hardware and communication}

At present, to implement EMPC in active smart buildings, the common practice is to connect an external MPC computational core with the building's automation system (BAS). This requires specification on what signals to be communicated, a communication protocol, and the implementation of mechanisms to handle communication and optimization problems (e.g. infeasibility or too long computation time). The other potential solution is to "Bring EMPC to Chips", for example, integration of EMPC into the Programmable Logic Controller (PLC) [33,34]or Field- Programmable Gate Array (FPGA) [35,36], which has been widely investigated in BAS as field controllers.

In addition, the sensors, actuators, smart meters and communication devices in the EMPC system should be able to proactively detect and to handle communication and other failures. Moreover, to reduce the hardware investment on implementation of EMPC for ADSM, it is necessary to optimize the installation allocation of the smart meters and sensors.

\subsubsection{Objective function \& multi-objective optimization}

Optimization is an indispensable part of EMPC functionality, wherein it is applied towards the economic optimization and constraint handling objectives. The objective function of EMPC for ADSM is always needed to consider trade-offs among multiple objectives, including economic operation based on time-of-use pricing and feed-in tariff, maximization of wind and PV production, maximization of user comfort, etc. In EMPC, it is common to choose the structure of the objective function such that the optimal objective forms a Lyapunov function for the closed loop system, and hence will guarantee stability [37]. In practice, this requirement is generally relaxed for stable systems with slow dynamics, such as active buildings for ADSM.

In addition, the objective function is applicable only when the solution exists within limits. The original optimization objectives, however, needs to be redefined, if a solution does not exist within the predefined limits, and in such cases the optimizer should have the means (e.g. soft constraints) to recover online from the infeasibility. The existing recovery techniques are based on the priorities of the constrained and controlled variables $[38,39]$.

\subsubsection{State estimation}

In EMPC for ADSM, besides potentially modelling errors and disturbances as occupation, open windows or high wind speed affect the thermal dynamics of the buildings. In order to achieve offset free control for the EMPC a proper disturbance model is needed. Ref. [40] found that a number of integrating disturbances equal to the number of measured states are sufficient to reach offset free control. In addition, all future (control) predictions begin from an 
initial state. The system model should be initialized to the measured/estimated current state of the building. Depending on what the state of the building is described, it might be impossible to measure everything directly. In the above two cases, a Kalman filter is the solution to the central state estimation problem in EMPC, which can be used to estimate the current state of the building and the estimation is used as initial/current state for control [14,41].

\section{Pilot testing}

The EMPC strategy for an active smart building was applied to a residential building-PowerFlexHouse3 (see Fig. 1). The PowerFlexHouse 3 facilities at the Technical University of Denmark (DTU), Risø campus have been equipped with sensors and controllable loads and heating equipment. They are interconnected in a configurable $400 \mathrm{~V}$ microgrid and communication platform [42]. The PowerFlexHouse 3 is a $150 \mathrm{~m}^{2}$ 3-floor house built in 1954 [43]. The outer walls of the house are brick constructed with a layer of insulation between them and the roof is tile. All sensors (temperature, motion and contacts, etc.) in PowerFlexHouse3 support KNX standard communication. There are four types of water-based heating radiators in the building [44]. In the basement there are three radiators of $2.708 \mathrm{~kW}$ total power; in the first floor there are 6 radiators of $6.138 \mathrm{~kW}$ total power and in the second floor there are 2 radiators of $2.198 \mathrm{~kW}$ total power. The total power consumption of the heating radiators is around $11 \mathrm{~kW}$ and they can be remotely controlled via electro-valves. According to the national statistics, due to cold climates in the Nordic countries, space heating accounts for more than $60 \%$ of all energy use in buildings. The main objective of the developed EMPC controller is to realize the load shifting by using heating radiators in the PowerFlexhouse3. That is to say, to decrease peak load, reduce energy costs, and improve building thermal comfort, the other impactors, such as the windows area, solar irradiation, building envelope and heat capacity in different floors, which have strong influence on the interior thermal behaviour, are also considered in Section 3.1. The detailed parameters are listed in Table 1.

\subsection{Modelling}

The heat flow in PowerFlexHouse3 is modelled by a grey-box approach, using physical knowledge about heat transfer together with statistical methods of real measurement data to estimate model parameters. To reduce the complexity, in PowerFlexHouse3, each floor is considered as a single room where all the radiators are grouped as one input for each floor. The building's entrance is in a mid-way position between the first floor and the basement. It was decided to group it in the first floor. Heat transfer due to conduction, convection and ventilation is assumed to be linear with the temperature difference on each side of the medium. When

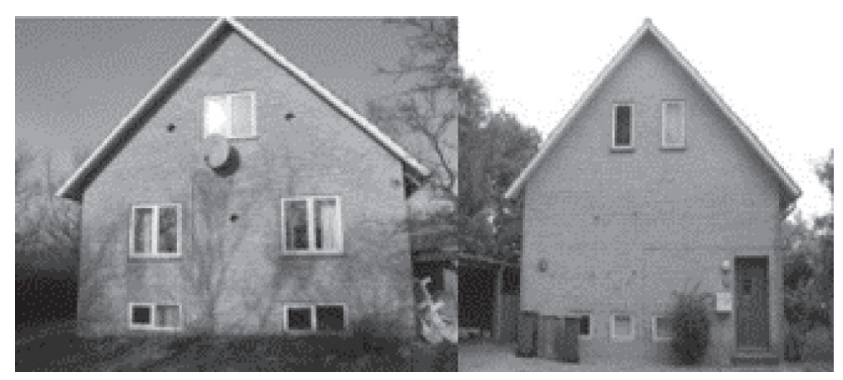

(a) Back facade

(b) Front facade
Table 1

Model parameters of PowerFlexHouse3.

\begin{tabular}{|c|c|c|}
\hline Symbols & Physical meaning & $\begin{array}{l}\text { Estimation } \\
\text { value }\end{array}$ \\
\hline$T_{f 1}, T_{f 2}, T_{b}$ & Temperature in floor 1 , floor 2 and basement & - \\
\hline $\begin{array}{c}T_{e 1}, T_{e 2} \\
T_{e b}\end{array}$ & $\begin{array}{l}\text { Envelope temperature in floor } 1 \text {, floor } 2 \text { and } \\
\text { basement }\end{array}$ & - \\
\hline$T_{\text {earth }}, T_{a}$ & Earth and ambient temperature & - \\
\hline $\begin{array}{l}\mathrm{p}_{\mathrm{H} 1}, \mathrm{p}_{\mathrm{H} 2} \\
P_{h b}\end{array}$ & Radiator power in floors $(\mathrm{kW})$ & - \\
\hline$P_{S}$ & Solar irradiation $\left(\mathrm{kW} / \mathrm{m}^{2}\right)$ & - \\
\hline$u_{i}$ & Control inputs & - \\
\hline$A w_{b}$ & Effective window area in basement $\left(\mathrm{m}^{2}\right)$ & 0.2110 \\
\hline$A w_{1}$ & Effective window area in floor $1\left(\mathrm{~m}^{2}\right)$ & 0.8915 \\
\hline$A w_{2}$ & Effective window area in floor $2\left(\mathrm{~m}^{2}\right)$ & 0.1526 \\
\hline$C_{f 1}$ & Heat capacity in floor $1(\mathrm{~kJ} / \mathrm{kg} \mathrm{K})$ & $1.0466 \times 10^{4}$ \\
\hline$C_{f 2}$ & Heat capacity in floor $2(\mathrm{~kJ} / \mathrm{kg} \mathrm{K})$ & $3.5417 \times 10^{3}$ \\
\hline$C_{b}$ & Heat capacity in basement $(\mathrm{kJ} / \mathrm{kg} \mathrm{K})$ & $3.6410 \times 10^{3}$ \\
\hline$C_{e 1}$ & $\begin{array}{l}\text { Heat capacity in floor } 1 \text { building envelope } \\
(\mathrm{kJ} / \mathrm{kg} \mathrm{K})\end{array}$ & $2.0929 \times 10^{4}$ \\
\hline$C_{e 2}$ & $\begin{array}{l}\text { Heat capacity in floor } 2 \text { building envelope } \\
(\mathrm{kJ} / \mathrm{kg} \mathrm{K})\end{array}$ & $1.6307 \times 10^{4}$ \\
\hline$C_{e b}$ & $\begin{array}{l}\text { Heat capacity in basement building envelope } \\
(\mathrm{kJ} / \mathrm{kg} \mathrm{K})\end{array}$ & $2.0860 \times 10^{4}$ \\
\hline$R_{f f}$ & Thermal resistance between floor 1 and $2(\mathrm{~K} / \mathrm{kW})$ & 4.249 \\
\hline$R_{f b}$ & $\begin{array}{l}\text { Thermal resistance between floor } 1 \text { and basement } \\
(\mathrm{K} / \mathrm{kW})\end{array}$ & 3.7129 \\
\hline$R_{e 1 a}$ & $\begin{array}{l}\text { Thermal resistance between floor } 1 \text { envelope and } \\
\text { ambient }(\mathrm{K} / \mathrm{kW})\end{array}$ & 13.934 \\
\hline$R_{e 2 a}$ & $\begin{array}{l}\text { Thermal resistance between floor } 2 \text { envelope and } \\
\text { ambient }(\mathrm{K} / \mathrm{kW})\end{array}$ & 24.562 \\
\hline$R_{e b e}$ & $\begin{array}{l}\text { Thermal resistance between basement envelope } \\
\text { and earth }(\mathrm{K} / \mathrm{kW})\end{array}$ & 15.546 \\
\hline$R_{f 1 e 1}$ & $\begin{array}{l}\text { Thermal resistance between floor } 1 \text { and its } \\
\text { envelope }(K / \mathrm{kW})\end{array}$ & 0.65327 \\
\hline$R_{f 2 e 2}$ & $\begin{array}{l}\text { Thermal resistance between floor } 2 \text { and its } \\
\text { envelope }(K / \mathrm{kW})\end{array}$ & 3.6202 \\
\hline$R_{b e b}$ & $\begin{array}{l}\text { Thermal resistance between basement and its } \\
\text { envelope }(K / k W)\end{array}$ & 3.0275 \\
\hline
\end{tabular}

assuming these properties, the heat model can be formulated as an equivalent electric circuit with resistors and capacitors (RCnetwork). In such an RC-network, the resistors can be regarded as resistance to transfer heat and the capacitors as heat storage. The RC-network for the heat dynamic model for PowerFlexHouse3 is shown in Fig. 2. The heat transfer model takes measured disturbances namely the solar irradiance $P_{s}\left(\mathrm{~kW} / \mathrm{m}^{2}\right)$, the ambient temperature $T_{a}\left({ }^{\circ} \mathrm{C}\right)$ and the earth temperature $T_{\text {earth }}\left({ }^{\circ} \mathrm{C}\right)$ into consideration. Ventilation does not directly cause heat transfer, but due to mass transfer heat is transferred. It is considered the wind speeds up to $5 \mathrm{~m} / \mathrm{s}$ in the thermal resistance of the building walls as shown in [27] and high wind speeds are considered as a noise term. This approximation is invalid for higher wind speeds where it becomes non-linear [30]. The heat flux $\left(u_{i} P_{h i}\right)$ coming from the heaters in each floor is the controlled input in the model. The solar irradiation goes through the effective windows surface directly into the rooms and is described in the model as $\left(A_{w i} P_{s}\right)$.

The first-order heat dynamics for the PowerFlexHouse 3 are represented by the stochastic differential equations (SDEs) (2a)-(2c) for the floors, and equations (2d) and (2f) for the building envelopes, respectively, where $\boldsymbol{t}$ is the time. The term $\sigma_{i} \mathrm{~d}_{\omega \mathrm{i}} / d t$ represents the process noise; where $\omega_{i}$ are standard Wiener processes with the variances $\sigma_{i}$. Table 1 presents the relevant parameters and variables, regarding the characteristics of the building illustrated by Fig. 2 and Eqs. (2a)-(2f).

$$
\begin{aligned}
\frac{d T_{f 1}}{d t}= & \frac{1}{R_{f f} C_{f 1}}\left(T_{f 2}-T_{f 1}\right)+\frac{1}{R_{f b} C_{f 1}}\left(T_{b}-T_{f 1}\right)+\frac{1}{R_{f 1 e 1} C_{f 1}}\left(T_{e 1}-T_{f 1}\right) \\
& +\frac{P_{h 1} u_{1}}{C_{f 1}}+\frac{A w_{1} P_{s}}{C_{f 1}}+\sigma_{f 1} \frac{d w_{1}}{d t}
\end{aligned}
$$

Fig. 1. A residential building-PowerFlexHouse3 


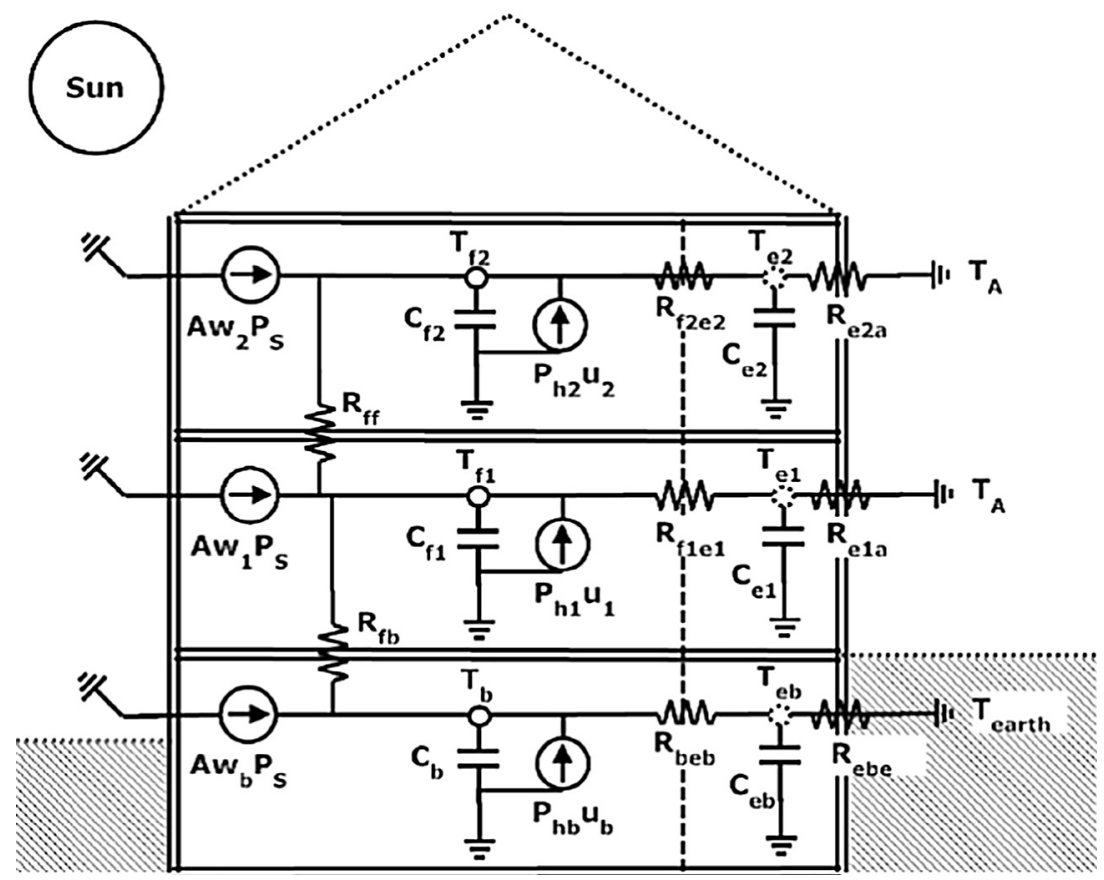

Fig. 2. Heat dynamics RC-network of the PowerFlexHouse3.

Table 2

Comparison of developed statistical models with physically estimated values.

\begin{tabular}{|c|c|c|c|c|c|}
\hline \multirow[t]{2}{*}{ Time sample (min) } & \multirow[t]{2}{*}{ Physical estimation } & \multicolumn{4}{|l|}{ Model } \\
\hline & & $\begin{array}{l}\boldsymbol{T}_{\boldsymbol{i}} \\
30\end{array}$ & $\begin{array}{l}\boldsymbol{T}_{\boldsymbol{i}} \\
60\end{array}$ & $\begin{array}{l}\boldsymbol{T}_{\boldsymbol{i}} \boldsymbol{T}_{\boldsymbol{e}} \\
30\end{array}$ & $\begin{array}{l}\boldsymbol{T}_{\boldsymbol{i}} \boldsymbol{T}_{\boldsymbol{e}} \\
60\end{array}$ \\
\hline Floor $2 C_{\text {total }}(\mathrm{kJ} / \mathrm{K})$ & 18,125 & 7639 & 8588 & 18,400 & 19,800 \\
\hline Floor $1 C_{\text {total }}(\mathrm{kJ} / \mathrm{K})$ & 32,936 & 23,706 & 23,283 & 30,152 & 31,000 \\
\hline Basement $C_{\text {total }}(\mathrm{kJ} / \mathrm{K})$ & 32,936 & 12,456 & 13,718 & 28,125 & 24,500 \\
\hline Floor $2 R_{\text {total }}(\mathrm{K} / \mathrm{kW})$ & 37.6 & 11.9 & 12.13 & 21.7 & 28.2 \\
\hline Floor $1 R_{\text {total }}(\mathrm{K} / \mathrm{kW})$ & 27.3 & 11.9 & 12.13 & 13.4 & 14.6 \\
\hline Basement $R_{\text {total }}(\mathrm{K} / \mathrm{kW})$ & 39.4 & 14.3 & 13.7 & 14 & 18.6 \\
\hline
\end{tabular}

$$
\begin{aligned}
\frac{d T_{f 2}}{d t}= & \frac{1}{R_{f f} C_{f 2}}\left(T_{f 1}-T_{f 2}\right)+\frac{1}{R_{f 222} C_{f 2}}\left(T_{e 2}-T_{f 2}\right)+\frac{P_{h 2} u_{2}}{C_{f 2}} \\
& +\frac{A w_{2} P_{s}}{C_{f 2}}+\sigma_{f 2} \frac{d w_{2}}{d t}
\end{aligned}
$$

$$
\begin{aligned}
\frac{d T_{b}}{d t}= & \frac{1}{R_{f b} C_{f b}}\left(T_{f 1}-T_{b}\right)+\frac{1}{R_{b e b} C_{f b}}\left(T_{e b}-T_{b}\right) \\
& +\frac{P_{h b} u_{b}}{C_{f b}}+\frac{A w_{b} P_{s}}{C_{f b}}+\sigma_{b} \frac{d w_{b}}{d t}
\end{aligned}
$$

$\frac{d T_{e 1}}{d t}=\frac{1}{R_{e 1 a} C_{e 1}}\left(T_{a}-T_{e 1}\right)+\frac{1}{R_{f 1 e 1} C_{e 1}}\left(T_{f 1}-T_{e 1}\right)+\sigma_{e 1} \frac{d w_{1}}{d t}$

$\frac{d T_{e 2}}{d t}=\frac{1}{R_{e 2 a} C_{e 2}}\left(T_{a}-T_{e 2}\right)+\frac{1}{R_{f 2 e 2} C_{e 2}}\left(T_{f 2}-T_{e 2}\right)+\sigma_{e 2} \frac{d w_{2}}{d t}$

$\frac{d T_{e b}}{d t}=\frac{1}{R_{e b e} C_{e b}}\left(T_{e a r t h}-T_{e b}\right)+\frac{1}{R_{b e b} C_{e b}}\left(T_{b}-T_{e b}\right)+\sigma_{e b} \frac{d w_{b}}{d t}$

The parameters of the SDEs were estimated using a PRBS which provides the flexibility to extend the model up to several states as stated in [45]. PRBS is a deterministic random signal with white noise characteristics sent to the controllable inputs of the plant, namely the heaters in each floor. Measurement data of the ambient temperature, solar irradiation, floor temperatures, wind speed and direction were taken in a 3-week experimental set in spring 2013
[46]. All inner doors were assumed to be opened while all windows and doors to the outside were considered to be closed. The parameter estimation, whose values are presented in Table 1, was realized using maximum likelihood estimation with CTSM-R [47], a software tool for estimating embedded parameters in a continuous time stochastic state space model, developed at DTU Department of Applied Mathematics and Computer Science. From this process the estimated values, the corresponding standard error, the value of the $t$-statistic and associated probabilities for testing the validation of the parameters are calculated to assure the accuracy and reliability of the parameters' evaluation. Actually, a simple model that only includes one state variable-the indoor temperature $\boldsymbol{T}_{\boldsymbol{i}}$ $\left[\begin{array}{lll}T_{f 1} & T_{f 2} & T_{b}\end{array}\right]$ of different floors with different sample time, was also built and validated [48]. As shown in Eqs. (2a)-(2f), the model provides a more detailed knowledge of the dynamics of the building by augmenting the state space with the introduction of the envelope temperature $\boldsymbol{T}_{\boldsymbol{e}}\left[T_{e 1} T_{e 2} T_{e b}\right]$. Adding the external envelope of the building, a heat capacity $\left[C_{e 1} C_{e 2} C_{e b}\right]$ is also formed giving increased inertia to the heat dynamics of the building. Comparing the total heat capacity and total thermal resistance of the building physical estimation with the developed statistical models, the $\boldsymbol{T}_{\boldsymbol{i}} \boldsymbol{T}_{\boldsymbol{e}}$ $\left[T_{f 1} T_{f 2} T_{b} T_{e 1} T_{e 2} T_{e b}\right]$ model with the sample time of 60 min shown in Eqs. (2a)-(2f) can describe the heat dynamics of the building much better and much closer to reality, although some parameters' values (which have very small standard errors but with unrealistic physical meaning), such as the values of thermal resistance between floor envelope and ambient are bigger than the value of 


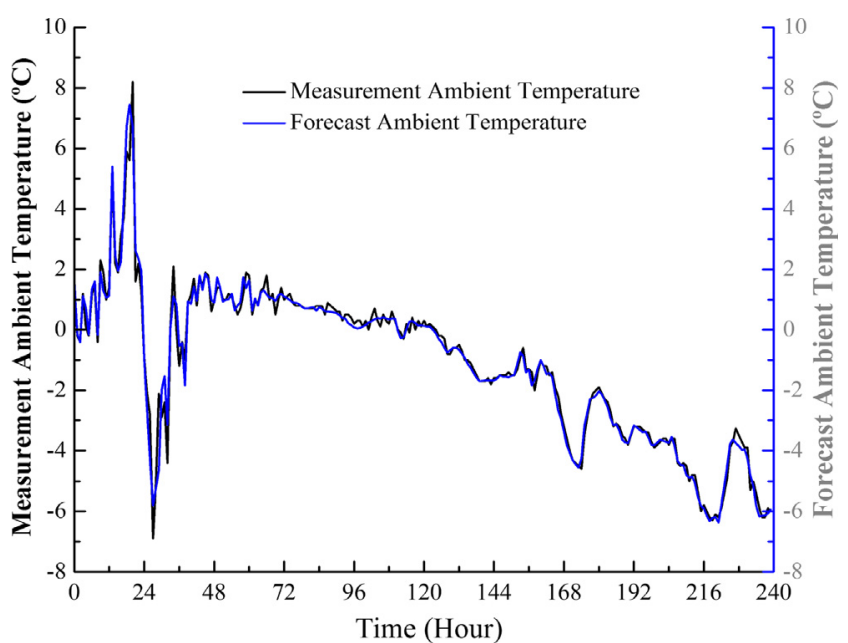

(a) Forecast ambient temperature (blue) and actual measuring ambient temperature (black)

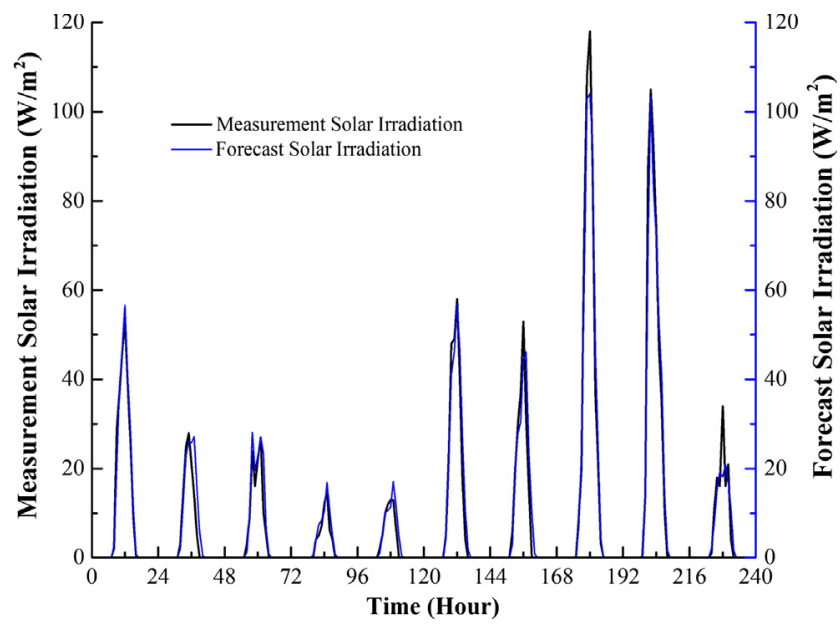

(b) Forecast solar irradiation (blue) and actual measuring acutal measuring solar irradiation (black)

Fig. 3. Comparison between the weather forecast data and actual measuring weather data. the general physical evaluation. This $\boldsymbol{T}_{\boldsymbol{i}} \boldsymbol{T}_{\boldsymbol{e}}$ model still can provide a relative detailed knowledge of the building's heat dynamics for the EMPC controller design. The detailed description of building's models and the models' validation for PowerFlexHouse 3 can be found in Ref. [48] (see Table 2).

\subsection{EMPC formulation}

In the pilot testing study, the objective function was formulated as (1a), where $c^{\prime}$ is a vector with the price signals broadcasted by an aggregator, central controller or a power provider, $u_{k}$ is the optimized power consumed by the radiators in order to heat the PowerFlexHouse 3 and $N$ is the length of the prediction horizon (for example $12 \mathrm{~h}$ ). The index $k$ stands for the iteration in the prediction horizon.

Concerning the bound constraints, the radiators are only able to give off a certain amount of heat, therefore the solution is subject to (1d); an output (inside temperature) constraint is required, which is defined by (1f); The output constraints $Z_{k}^{\min }$ and $Z_{k}^{\max }$ represent the predefined limits of the comfort temperature bands in the zones and can be set independently for each zone. For example, the residential building PowerFlexHouse 3 has requirements on the inside temperature from $21^{\circ} \mathrm{C}$ to $23^{\circ} \mathrm{C}$ during 8:00-19:00. According to [49] based on ISO 7730 a bandwidth of operative temperature in regular buildings from $21^{\circ} \mathrm{C}$ to $23{ }^{\circ} \mathrm{C}$ reach $90 \%$ acceptability from the inhabitants in winter, whereas a temperature band from $19{ }^{\circ} \mathrm{C}$ to $25^{\circ} \mathrm{C}$ is for $70 \%$ acceptance. It is assumed that the average temperature and in the same way the comfort zone can be softly lowered during the night by $1{ }^{\circ} \mathrm{C}$. (See the low/high temperature reference curves in Figs. 7, 9 and 11.)

The model formulated in Eqs. (2a)-(2f) and the parameters estimated and presented in Table 1 were used as the constraints presented in Eqs. (1b) and (1c).

\subsection{Input data and State Estimation}

The proposed EMPC controller considers electricity prices, ambient temperature and solar irradiation data for the predictions. The input data were taken from 17.01.2014 until 26.01.2014 a total of 10 days. The dynamic price signals were obtained from the Nord Pool spot DK1 market [25]. The local forecast data of the ambient

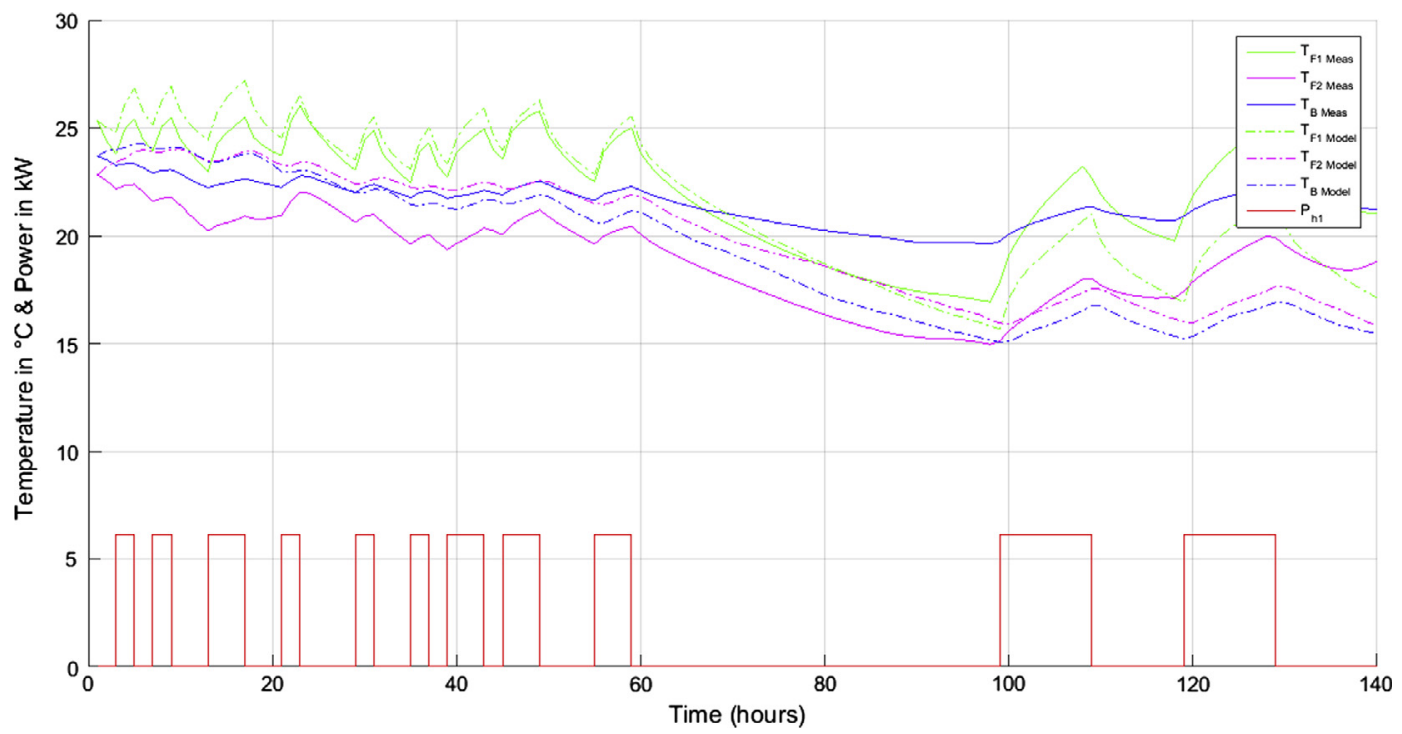

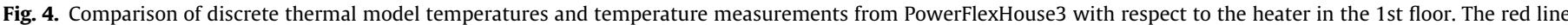

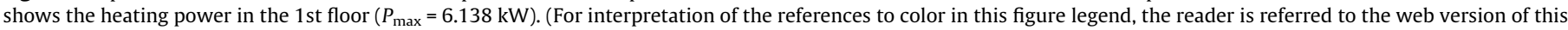
article.) 


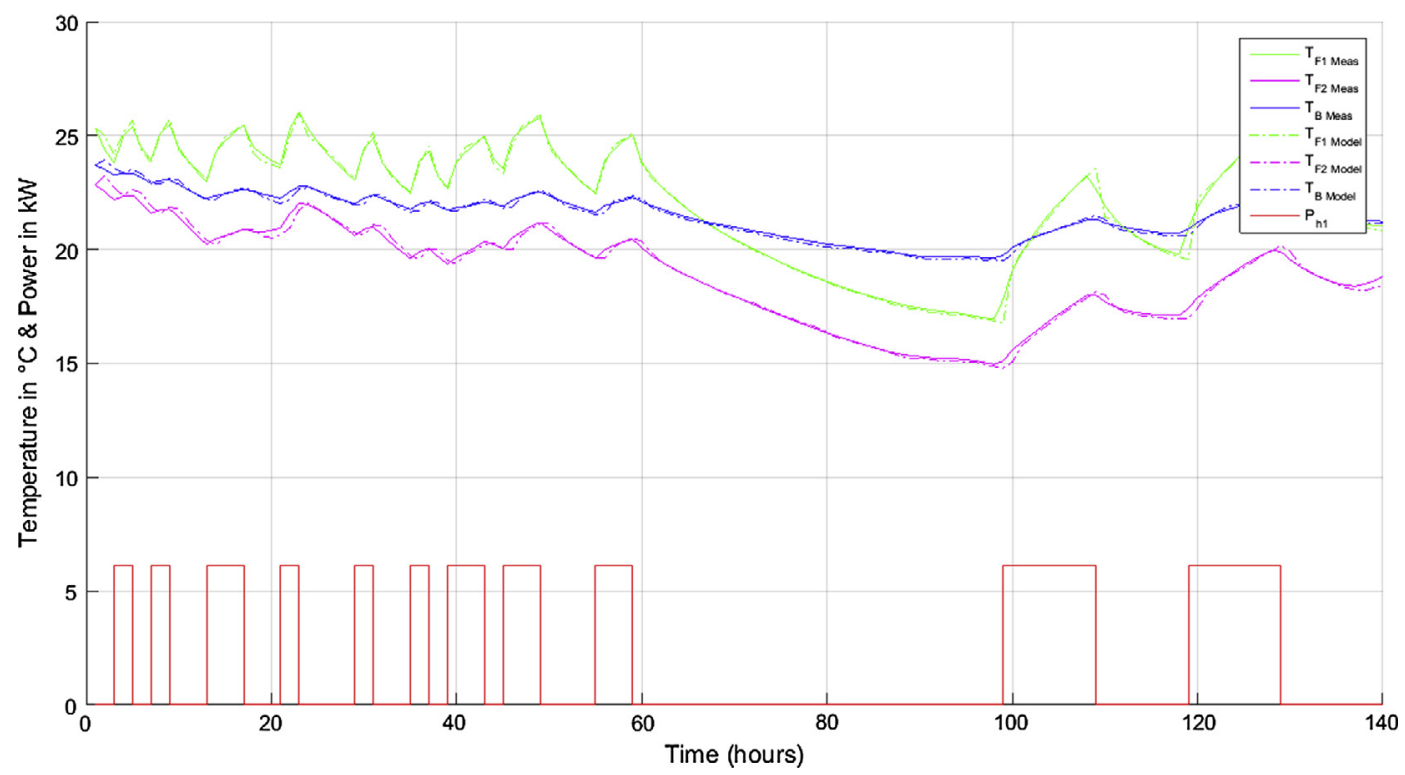

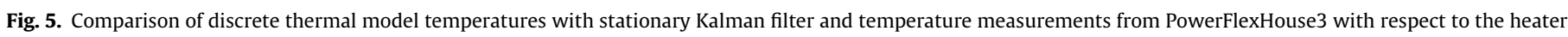

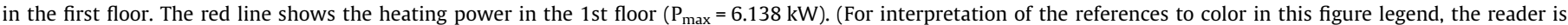
referred to the web version of this article.)

(outdoor) temperature $T_{a}$ and the solar irradiation $P_{S}$ are updated twice a day for the next $48 \mathrm{~h}$, which are provided by the meteorology group in Wind Energy Division at DTU Risø campus. The meteorological data comes from a mesoscale reanalysis system using the method described in Refs. [50,51]. The maximum relative error between the actual measurement and the forecast data of the wind and solar irradiation are $8.7 \%$ and $7.9 \%$ respectively during the 10 days' test period (see Fig. 3). Therefore, we concluded that the local weather forecast data are available to be integrated into the EMPC control strategy. Otherwise, to overcome a bigger weather forecast error, the weather actual measuring data (ambient temperature and solar irradiation, etc.) could be integrated with the prediction model for the building indoor air temperature, and verifies the predictive values. Then we could use the process's real-time output (the actual measuring inside air temperature) and model's (previous) predictive output to structure one model output feedback correction.

In addition, because of the model's uncertainty and disturbances such as building occupation, open windows or high wind speed, as shown in Fig. 4, the developed model without any observer implementation is not capable to precisely predict the future behaviour of the residential building. There were big errors between the actual temperature measurement and model's calculation for the first floor's temperature in Fig. 4. Moreover, not all states of the control model can be measured (for example the envelop temperature of the building), and state estimation is a required step in MPC scheme. The state estimation problem boils down to examining the past monitoring data and reconciling these measurements with the model to determine the most likely value of the state at the current time. To diminish their impacts and increase the model's accuracy, for linear models, the optimal state estimation problem has an offline well known solution, one stationary Kalman filter can be introduced and its impact can be observed in Fig. 5 [41].

\section{Results analysis and discussion}

Figs. 7, 9 and 11 demonstrate the good performance of the inside temperature of three different floors in PowerFlexHouse 3 during the test period. The inside temperatures are controlled in the reference band following the comfort pattern with the predictive occupancy. Figs. 6, 8 and 10 show the preheating strategy of EMPC - from the midnight to the early morning, the electricity price is much lower and there is higher power consumption (because the much lower power spot price always happened during 22:00-6:00 in Denmark [25]) and the temperature of the first floor (mainly a living room and a kitchen) is always approaching to the higher reference during this period (see Fig. 7) to preheat the building for the usage in morning, while the temperature on the second floor (mainly bedrooms) and basement always follow the lower reference (see Figs. 9 and 11) satisfied with user's different behaviour requirements meanwhile saving energy cost. The radiators in PowerFlexHouse 3 as shown in Figs. 6, 8 and 10, even if work during the daytime, they all occurred when there is a lower price during the daytime. All these results further illustrate that EMPC control strategy can achieve energy savings by shifting load from on-peak to off-peak period and meet the end-users' comfort and their behaviour requirements.

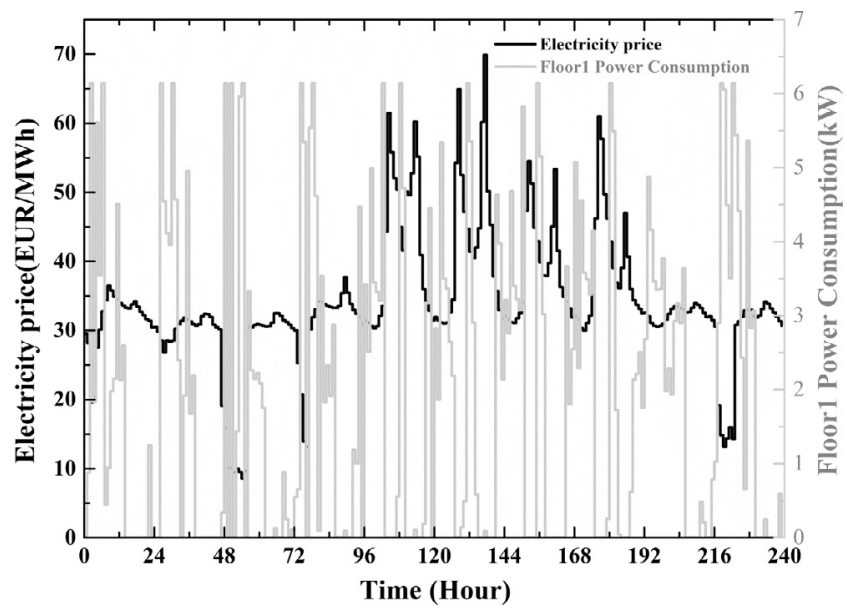

Fig. 6. EMPC with prediction horizon $\mathrm{N}=5 \mathrm{~h}$ : the optimized predictive power consumption on the first floor of PowerFlexHouse3 (the black curve is the corresponding varying electricity price). 


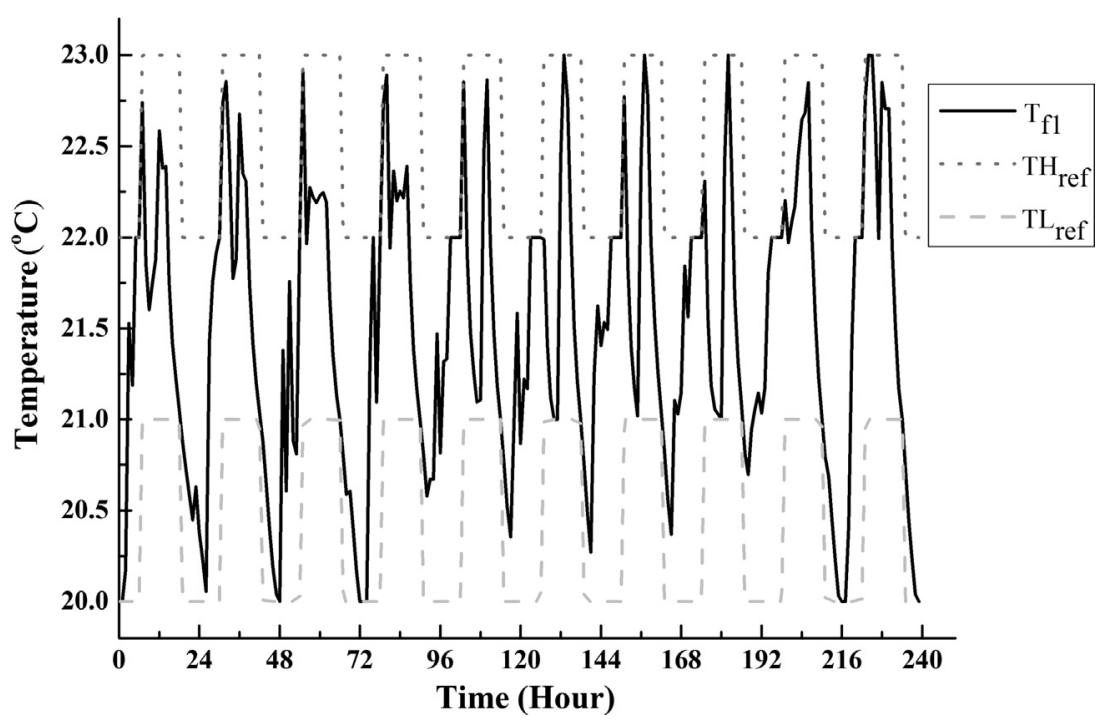

Fig. 7. EMPC with prediction horizon $\mathrm{N}=5 \mathrm{~h}$ : the first floor inside temperature of PowerFlexHouse 3 related to the optimized the power consumption shown in Fig. 6 .

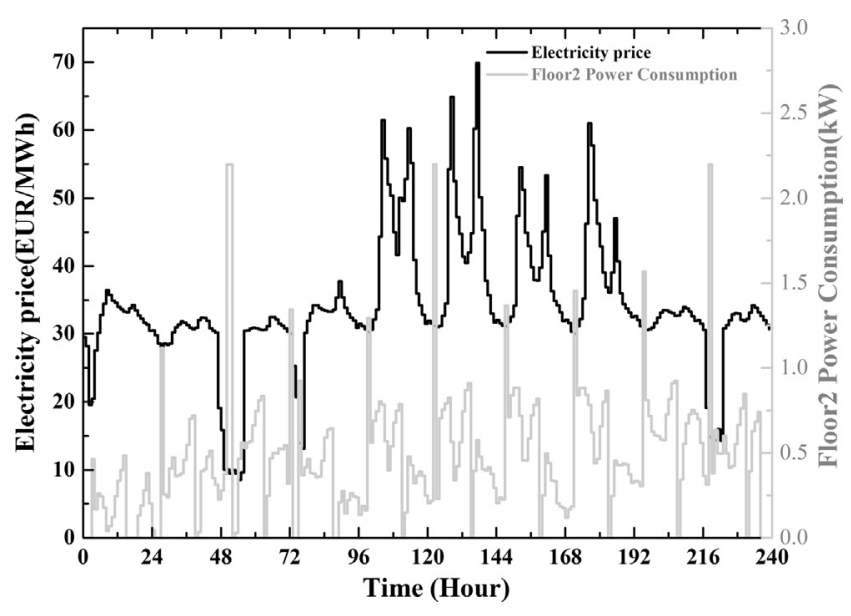

Fig. 8. EMPC with prediction horizon $\mathrm{N}=5 \mathrm{~h}$ : the optimized predictive power consumption on the second floor of PowerFlexHouse3 (the black curve is the corresponding varying electricity price).
In addition, it can be observed in Figs. 6 and 7 that the electrical heater on the first floor is much more "active" than the heaters on the other floors, resulting in the temperature of the first floor is more variable than the other floors' temperature. On the one hand, there are six radiators on first floor which can be operated; on the other hand, the first floor has a strong thermal interaction among the basement and the second floor. To some large scale applications, the thermal interactions between neighbouring zones/building blocks cannot be negligible, such that we need to use the decentralized MPC or distributed MPC. At the same time, for large multi-zone buildings, even simple mathematical models describing the building's thermal dynamics can result in a long computation time for the optimal control inputs, in particular when a centralized MPC approach is considered. An alternative consists in using a distributed MPC [52]. By using distributed MPC, the overall computation time can be significantly reduced; meanwhile, the robustness of the whole control system can be increased. However, this solution completely depending on the communication support and how good the sub-optimal performance is.

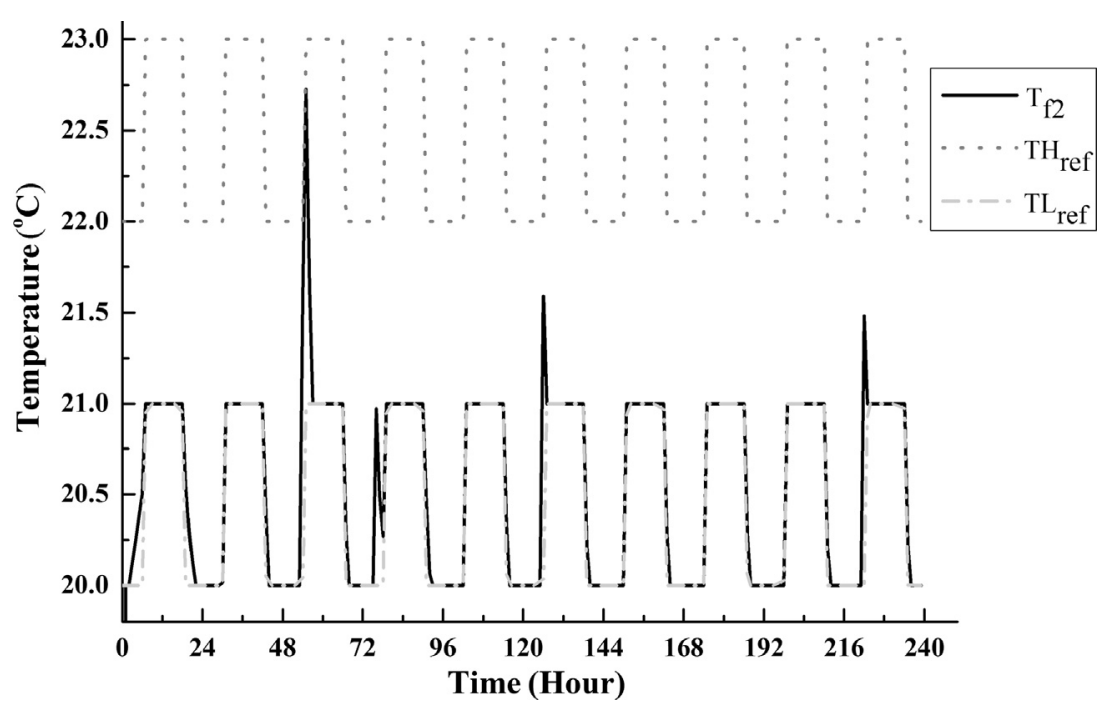

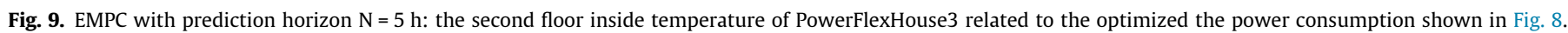




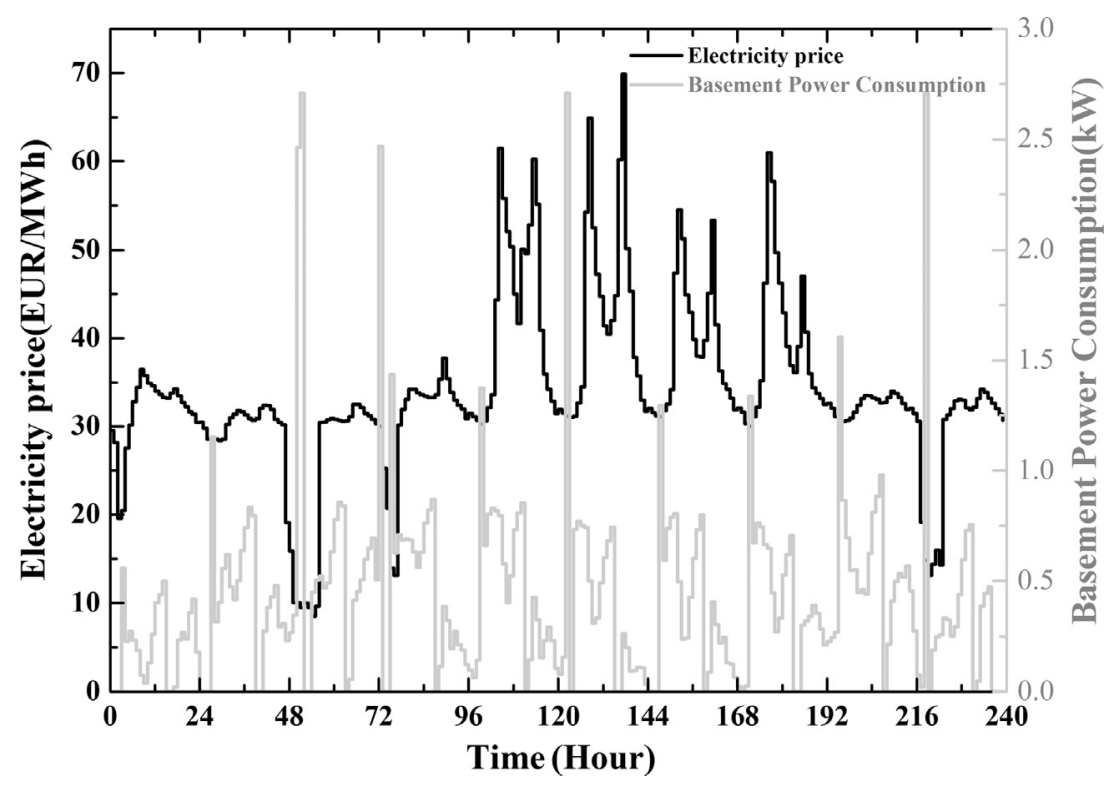

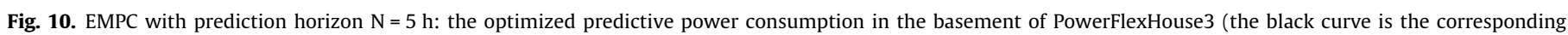
varying electricity price).

Table 3

Electricity costs and energy consumption for 10 days in January 2014.

\begin{tabular}{|c|c|c|c|c|}
\hline & & Electricity costs in EUR (for 10 days) & Energy consumption in $\mathrm{kW} \mathrm{h}$ & Relative costs in EUR cent/kW h \\
\hline PID low & & 23.15 & 684.1 & 3.38 \\
\hline PID average & & 25.35 & 742.4 & 3.41 \\
\hline \multirow[t]{11}{*}{ EMPC with prediction horizon $\mathrm{N}=$} & 1 & 23.61 & 687.4 & 3.43 \\
\hline & 2 & 23.24 & 689.1 & 3.37 \\
\hline & 3 & 22.83 & 691.6 & 3.30 \\
\hline & 4 & 22.53 & 699.5 & 3.22 \\
\hline & 5 & 22.49 & 706.7 & 3.18 \\
\hline & 6 & 22.72 & 710.5 & 3.20 \\
\hline & 7 & 23.13 & 713.7 & 3.24 \\
\hline & $\ldots$ & $\ldots$ & $\ldots$ & $\ldots$ \\
\hline & 12 & 23.91 & 727.1 & 3.23 \\
\hline & $\ldots$ & $\ldots$ & $\ldots$ & $\ldots$ \\
\hline & 24 & 24.03 & 729.4 & 3.29 \\
\hline
\end{tabular}

In order to compare the controller performance in terms of energy costs, a scenario is implemented where the investigated building is equipped with traditional set point based thermostatic controllers namely Proportional-Integral-Differential (PID) controller. Due to the fact that the EMPC normally does not trace a fixed reference temperature trajectory, two reference scenarios are proposed. In the so called PID low temperature scenario the lower band temperature is continuously traced for all zones. In the PID average temperature scenario the controllers reference temperature is the average comfort zone temperature. Both scenarios fulfil the temperature specification but they differ in terms of provided heat. For these two reference scenarios, the simulations were conducted under the same conditions as EMPC running. In other words, for each control strategy listed in Table 3, PID low/average controllers were simulated in the same test period of EMPC controller, with the same weather and energy prices input data. In Table 3, the results of the scenarios' analysis are presented by electricity costs in EUR for the designed controllers (i.e. PID low/average and EMPC controllers), the corresponding energy consumption can be expressed in $\mathrm{kW}$ h and the relative energy costs, which is the ratio between the electricity costs and the energy consumption. It is obviously that the electricity cost and energy consumption of the PID low controller are much lower than those of the PID average controller because of its lower set points for the reference temperature. Comparing with the two reference scenarios (PID low/average), EMPC controller demonstrates that its energy consumption (and the provided heat) increases with the EMPC prediction horizon. Both the costs of electricity and the relative cost of EMPC controller firstly decrease with the prediction horizon increases and reach the minimum with the prediction horizon $\mathrm{N}=5 \mathrm{~h}$. The results also illustrate that the importance on how to tune the prediction horizon, which will play a great influence on the EMPC controller performance.

Although the electricity cost of EMPC controller are not much significant when compared them with the PID solutions, the main achievement of EMPC controller is to demonstrate that buildings can provide "flexibility" services to the energy systems. Flexibility is considered as the ability of a system to respond to variability and uncertainty at different time scales and different locations. For energy system operation and dispatch planning, flexibility is of importance and has a significant commercial value. The demand side flexibility provided by the buildings considering the temperature comfort and the cost of energy, can be a great benefit for consumers and for DSM enabling integration of fluctuating renewables, such as wind and solar, to smooth out the peak demand which will have major impact on system reliability and generation cost. As illustrated in Figs. 6, 8 and 10, it is notable that the energy consumptions occur mainly at the low energy prices 


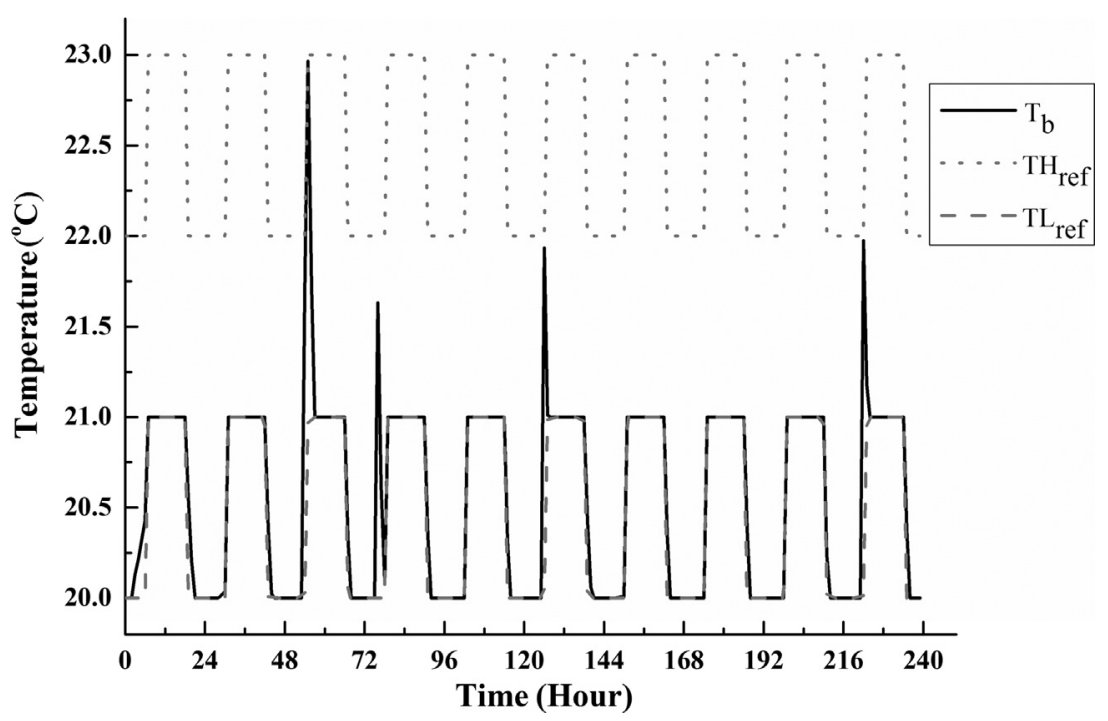

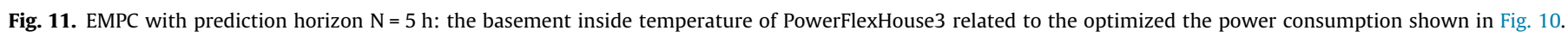

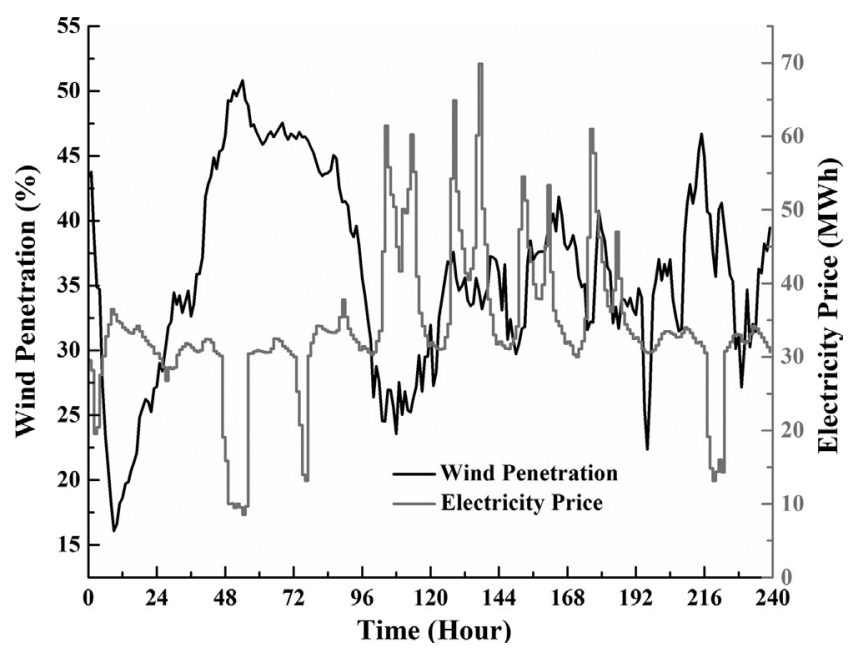

Fig. 12. Hourly electricity spot price and wind power penetration during the test period for DK-East.

periods, characterizing a high share of renewables (wind) in the grid, for example, according to the data provided by Energinet.dk [53] and Nordpool DK East market, the correlation between wind power penetration and a day-ahead electricity spot price is shown in Fig. 12. It is obviously that, for DK-East market where the test site-DTU Risø campus is located, the higher the wind power penetration, the lower the day-ahead hourly electricity spot price during the test period from January 17, 2014 to January 26, 2014. In one word, the proactive feature of EMPC is a must for the future smart energy systems.

\section{Conclusion}

In summary, to harness the full potential of the increased share of renewables, energy must be used more efficiently, effectively, and intelligently. Flexible consumption and smart energy systems must be developed with correlative dependence and interplay to meet the challenge of integrated fluctuating RESs. Buildings play a crucial role in this process, especially for buildings with large thermal storage capacity.
The pilot testing study demonstrated that EMPC implementation for active buildings is effective and attractive; but there are still some challenges, especially the forecast data; the compromise between the simplification and complication of the building thermal dynamic modelling for the predictive control to maximize its potential flexibility value; for the multi-objective optimization problems, how to guarantee a feasible optimal solution to meet the operation requirements of the multi-carrier energy system; etc., which need to be effectively handled in practice.

The future work will focus on adaptive and distributed MPC for buildings integrated into smart energy systems, including the adaptive models and comfort bands for the different seasons and user behaviour. In addition, the impact of models' accuracy and forecast data's precision on EMPC controller's performance will be further studied. Finally, how to best achieve the coordination between the widely used low-level control loops (switch/PID controller) and the top-level MPC-based energy management systems should also be considered.

\section{Acknowledgement}

This work is supported by "Energy Management Systems for Active Distribution Network (EMS4ADGrids)" project grant by the Danish Agency for Science, Technology and Innovation (No. 4070-00023B); and "PROActive INtegration of sustainable energy resources enabling active distribution networks (PROAIN)" project grant by the Danish Council for Strategic Research (No. 304500012B). The authors would like to express their appreciation to Andrea N. Hahmann, Senior Scientist, from Wind Energy Division of DTU, for her work on providing us with the local weather forecast data.

\section{References}

[1] A.V. Andersen, 42\%: Danish Wind Power Sets World Record, State of Green News 2016.01.15. <http://stateofgreen.com/en/news/42-danish-wind-powersets-world-record-again>.

[2] Danish Energy Agency, Energy Policy in Denmark, December, 2012. <http:// www.ens.dk/en/info/publications/energy-policy-denmark>.

[3] Vision for Smart Energy in Denmark, Smart Energy Networks, 2015. <http:// www.smartenergynetworks.dk/uploads/3/9/5/5/39555879/vision_for_smart_ energy_in_denmark.pdf>.

[4] International Energy Agency, Transition to Sustainable Buildings - Strategies and Opportunities to 2050, Edition: 2013, 2013. 
[5] White papers for a green transition: SMART BUILDINGS. <http://www. investindk.com/ /media/Files/Reports/Smart\%20Buildings\%20Whitepaper. ashx>.

[6] EnergyLab Nordhavn project. <http://www.energylabnordhavn.dk/>.

[7] iPower project. <http://www.ipower-net.dk/>.

[8] Ecogrid -EU project. <http://www.ipower-net.dk/>

[9] D.Q. Mayne, J.B. Rawlings, C.V. Rao, P.O.M. Scokaert, Constrained mode predictive control: stability and optimality, Automatica 36 (2000) 789-814.

[10] B.C. Ding, Modern Predictive Control, CRC Press, United States, 2010 (Chapter 1).

[11] R. Scattolini, Architectures for distributed and hierarchical model predictive control-a review, J. Process Control 19 (2009) 723-731.

[12] H. Jiang, J. Lin, Y. Song, S. You, Y. Zong, Explicit model predictive control applications in power systems: an AGC study for an isolated industrial system IET Gener. Transm. Distrib. (2016), http://dx.doi.org/10.1049/ietgtd.2015.0725 (Online ISSN 1751-8695, Available online: 15 January).

[13] B. Otomega, A. Marinakis, M. Glavic, T. Cutsem, Use of model predictive control for experimental microgrid optimization, Appl. Energy 115 (2014) 37-46.

[14] Y. Zong, D. Kullmann, A. Thavlov, O. Gehrke, H.W. Bindner, Application of mode predictive control for active load management in a distributed power system with high wind penetration, IEEE Trans. Smart Grid 3 (2) (2012) 1055-1062.

[15] J.B. Rawlings, R. Amrit, Optimizing process economic performance using mode predictive control, in: Nonlinear Model Predictive Control: Towards New Challenging Applications, Springer, 2009, pp. 119-138.

[16] M. Diehl, R. Amrit, J.B. Rawlings, A Lyapunov function for economic optimizing model predictive control, IEEE Trans. Autom Control 56 (3) (2011) 703-709.

[17] T. Trana, K.-V. Linga, Jan M. Maciejowskib, Economic model predictive control a review, in: the 31st International Symposium on Automation and Robotics in Construction and Mining (ISARC 2014).

[18] R. Halvgaard, N.K. Poulsen, H. Madsen, J.B. Jørgensen, Economic model predictive control for building climate control in a smart grid, in: 2012 IEEE PES Innovative Smart Grid Technologies (ISGT), 2012, pp. 1-6. http://dx.doi. org/10.1109/ISGT.2012.6175631.

[19] J. Ma, S.J. Qin, B. Li, T. Salsbury, Economic model predictive control for building energy systems, in: Innovative Smart Grid Technologies (ISGT), IEEE PES, 2011

[20] J. Ma, S.J. Qin, T. Salsbury, P. Xu, Demand reduction in building energy system based on economic model predictive control, Chem. Eng. Sci. 67 (1) (2012) 92100, 1 January.

[21] J. Ma, S.J. Qin, T. Salsbury, Experimental study of economic model predictive control in building energy systems, in: 2013 American Control Conference (ACC), June 17-19, Washington, DC, USA, 2013.

[22] M. Ellis, P.D. Christofides, Economic model predictive control with timevarying objective function: handling dynamic energy pricing and demand changes in process systems, in: Proceedings of 2013 AIChE Annual Meeting, San Francisco, CA, 2013.

[23] J.B. Rawlings, D. Angeli, C. Bates, Fundamentals of economic model predictive control, in: Proceedings of the IEEE Conference on Decision and Control, 2012, pp. 3851-3861.

[24] A. Zheng, M. Morari, Stability of model predictive control with soft constraints in: Proceedings of the 33rd IEEE Conference on Decision and Control, vol. 2 1994, pp. $1018-1023$.

[25] The Nord Pool spot market. <http://www.nordpoolspot.com/Market-data1/ Elspot/Area-Prices/SYS1/Hourly/?view=table>.

[26] H. Madsen, Statistical modelling of physical systems-an introduction to grey box modelling. <http://iiesi.org/assets/pdfs/101_madsen_4.pdf>.

[27] A. Thavlov, Dynamic optimization of power consumption, Master thesis, Kongens Lyngby, 2008.

[28] P. Bacher, H. Madsen, Identifying suitable models for the heat dynamics of buildings, Energy Build. 43 (2011) 1511-1522.

[29] K.K. Andersen, H. Madsen, L.H. Hansen, Modelling the heat dynamics of a building using stochastic differential equations, Energy Build. 31 (2000) 1324.
[30] A. Thavlov, H. Madsen, A non-linear stochastic model for an office building with air infiltration, Int. J. Sust. Energy Plann. Manage. 7 (2015) 59-70.

[31] M.J. Jimnez, H. Madsen, J.J. Bloem, B. Dammann, Estimation of non-linear continuous time models for the heat exchange dynamics of building integrated photovoltaic modules, Energy Build. 40 (2) (2015) 157-167.

[32] H. Huang, L. Chen, E. Hu, A hybrid model predictive control scheme for energy and cost savings in commercial buildings: simulation and experiment, in: Proceeding on 2015 American Control Conference, Palmer House Hilton, July 1-3, Chicago, IL, USA, 2015.

[33] B. Huyck, L. Callebaut, F. Logist, H.J. Ferreau, M. Diehl, J. De Brabanter, J. Van Impe, B. De Moor, Implementation and experimental validation of classic MPC on programmable logic controllers, in: 20th Mediterranean Conference on Control Automation (MED), 2012, pp. 679-684.

[34] A. Syaichu-Rohman, R. Sirius, Model predictive control implementation on a programmable logic controller for dc motor speed control, in: 2011 International Conference on Electrical Engineering and Informatics, 17-19 July, Bandung, Indonesia, 2011.

[35] K.V. Ling, S.P. Yue, J.M. Maciejowski, A FPGA implementation of model predictive control, in: Proceedings of the 2006 American Control Conference, June 14-16, Minneapolis, Minnesota, USA, 2006, pp. 1930-1935.

[36] N. Yang, D. Li, J. Zhang, Y. Xi, Model predictive controller design and implementation on FPGA with application to motor servo system, Control Eng. Pract. 20 (2012) 1229-1235.

[37] M. Diehl, R. Amrit, J.B. Rawlings, A Lyapunov function for economic optimizing model predictive control, IEEE Trans. Autom. Control 56 (3) (2011), March.

[38] J. Vada, O. Slupphaug, B.A. Foss, Infeasibility handling in linear MPC subject to prioritized constraints, in: IFAC'99 14th World Congress, 1999.

[39] W. Wojsznis, A. Mehta, P. Wojsznis, D. Thiele, T. Blevins, Multi-objective optimization for model predictive control, ISA Trans. 46 (2007) 351-361.

[40] G. Pannocchia, J. Rawlings, Disturbance models of offset-free model predictive control, AIChE J. 49 (2) (2003) 426-437.

[41] J. Široký, F. Oldewurtel, J. Cigler, S. Prívara, Experimental analysis of model predictive control for an energy efficient building heating system, Appl. Energy 88 (2011) 3079-3087.

[42] PowerLabDK. <http://www.powerlab.dk/Facilities/PowerFlexHouses>.

[43] OIS House Location, 2014. <https://www.ois.dk/default.aspx>.

[44] SMU. <http://smu.edu/geothermal/heatloss/heatloss.html>.

[45] P. Bacher, H. Madsen, Identifying suitable models for the heat dynamics of buildings, Technical report, DTU, 2011.

[46] M. Curzi, Modeling and system identification of Risø flexhouse, Master’s thesis, DTU, 2014.

[47] CTSM-R - Continuous Time Stochastic Modelling for R. <http://ctsm.info/>.

[48] K. Tsapralidis, Modelling, identification and control for heat dynamics of a three-storey brick house Master thesis, Technical University of Denmark, Kgs. Lyngby, 2014.

[49] J. van Hoof, J.L.M. Hensen, Quantifying the relevance of adaptive thermal comfort models in moderate thermal climate zones, Build. Environ. 42 (1) (2007) 156-170

[50] A.N. Hahmann, C.L. Vincent, A. Pena, J. Lange, C.B. Hasager, Wind climate estimation using WRF model output: Method and model sensitivities over the sea, Int. J. Climatol. 35 (2015) 3422-3439, http://dx.doi.org/10.1002/joc.4217.

[51] A.R. Mehrens, A.N. Hahmann, A.N. Hahmann, X.G. Larsén, L. von Bremen, Correlation of mesoscale wind speeds over the sea, Q. J. R. Meteorol. Soc. (2016), http://dx.doi.org/10.1002/qj.2900.

[52] P.D. Moroçan, R. Bourdais, D. Dumur, J. Buisson, A distributed MPC strategy based on Benders' decomposition applied to multi-source multi-zone temperature regulation, J. Process Control 21 (5) (2011) 729-737.

[53] Energinet.dk, 2016. <http://energinet.dk/EN/El/Engrosmarked/Udtraek-afmarkedsdata/Sider/default.aspx $>$. 